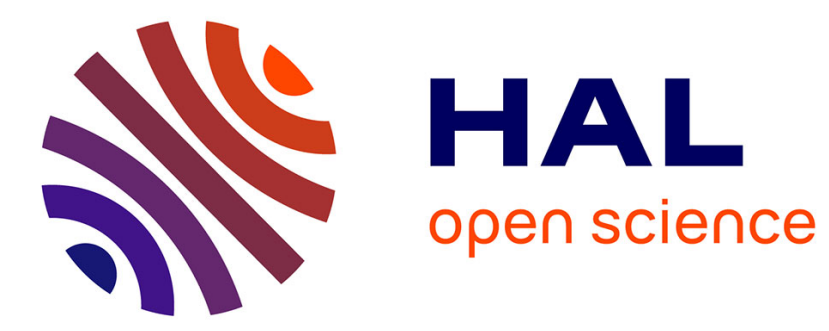

\title{
Shape Memory Effect and Properties Memory Effect of Polyurethane
}

\author{
Sedigheh Farzaneh, Joseph Fitoussi, Albert Lucas, Michel Bocquet, Abbass
}

Tcharkhtchi

\section{- To cite this version:}

Sedigheh Farzaneh, Joseph Fitoussi, Albert Lucas, Michel Bocquet, Abbass Tcharkhtchi. Shape Memory Effect and Properties Memory Effect of Polyurethane. Journal of Applied Polymer Science, 2013, 128 (5), pp.3240-3249. 10.1002/app.38530 . hal-00984685

\section{HAL Id: hal-00984685 \\ https://hal.science/hal-00984685}

Submitted on 30 Apr 2014

HAL is a multi-disciplinary open access archive for the deposit and dissemination of scientific research documents, whether they are published or not. The documents may come from teaching and research institutions in France or abroad, or from public or private research centers.
L'archive ouverte pluridisciplinaire HAL, est destinée au dépôt et à la diffusion de documents scientifiques de niveau recherche, publiés ou non, émanant des établissements d'enseignement et de recherche français ou étrangers, des laboratoires publics ou privés. 


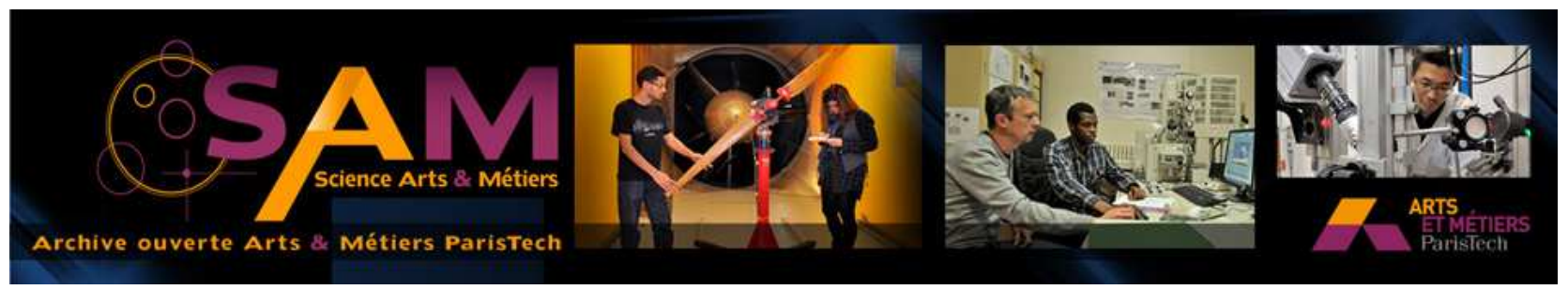

Science Arts \& Métiers (SAM)

is an open access repository that collects the work of Arts et Métiers ParisTech researchers and makes it freely available over the web where possible.

This is an author-deposited version published in: http://sam.ensam.eu Handle ID: .http://hdl.handle.net/10985/8054

\section{To cite this version :}

Sedigeh FARZANEH, Joseph FITOUSSI, Albert LUCAS, Michel BOCQUET, Abbass TCHARKHTCHI - Shape Memory Effect and Properties Memory Effect of Polyurethane - Journal of Applied Polymer Science - Vol. 128, n5, p.3240-3249 - 2013 


\title{
Shape Memory Effect and Properties Memory Effect of Polyurethane
}

\author{
S. Farzaneh, J. Fitoussi, A. Lucas, M. Bocquet, A. Tcharkhtchi \\ Art et Métiers ParisTech, UMR 8006, PIMM, 151 bd de l'Hopital, 75013 Paris, France \\ Correspondence to: A. Tcharkhtchi (E-mail: abbas.tcharkhtchi@ensam.eu)
}

\begin{abstract}
The relationship between shape and properties memory effect, especially viscoelastic properties of polyurethane under study is the main aim of this research work. Tensile tests have been performed in order to introduce $100 \%$ of deformation in the polyurethane samples. Under this deformation, stress-relaxation experiments have been performed in order to eliminate the residual stresses. This deformation of the samples has been fixed by cooling. Recovery tests, then, were carried out at different isothermal temperatures that varied from $30^{\circ} \mathrm{C}$ t $060 \mathrm{C}$. Viscoelastic behavior has been studied by a biparabolic model and by using the Cole-Cole method. It was shown that this model describes the behavior of the polymer at the different states of shape memory tests. The constants of this model then have been determined. This study leads to a better understanding of the mechanism of shape memory effect. The comparison between the virgin polymer and the polymer after a recovery test by DMTA (dynamic mechanical thermal analysis) and by Cole-Cole method has illustrated that the polymer does not obtain its initial properties even when it was totally regained its initial shape. These results have been confirmed by three successive shape memory tests on the same sample and by comparing the mechanical characteristics of different cycles because "shape memory effect" and "properties memory effect" do not follow the same mechanisms.
\end{abstract}

\section{INTRODUCTION}

The shape memory polymers (SMPs) are able to present single or multiple shape changes, ${ }^{1-6}$ when they are activated by external stimuli like thermal energy. This behavior applies to these polymers' broad fields of application. ${ }^{7-11}$ For example, in manufacturing of micro-biomedical components and medical devices, smart textiles, sensors, aerospace deployable equipments, and so on.

The polymers can show shape memory effect (SME) when they are able to present two different mechanical behaviors related to two distinct (hard and soft) morphologies. ${ }^{12,13}$ The hard morphology stabilizes the permanent shape of the structure, whereas the soft morphology allows the passage from permanent to temporary state or vice versa.

In the case of crosslinked polyurethanes (thermosets and elastomers), the crosslinking points and the segments of the isocyanate molecules directly linked to these points may be considered as the hard zones of the morphology; because there is not a significant local molecular motion in these zones. These zones are responsible of permanent state of the polymer.

Between the crosslinking points and isocyanate molecules, the molecular chains (related to polyols) are generally long and with more mobility. If the $\beta$-transition temperature of polymer is lower than the room temperature (which is the case), it will be ductile and may show high deformation capacity during tensile test. In this case, the molecular chains of soft segments may be stretched and oriented in the direction of the applied load. Releasing a stretched sample above its glass transition temperature, allows the sample to return to its initial position and to regain its original shape. However, it is possible to fix this temporary shape by cooling the sample after stretching it.

The soft segments of polyurethane may be used as a kind of molecular switch, when the stretched network is thermally stimulated. This switching permits the recovery and the regain of initial shape. To have the switching function, the soft segment must be heated at a temperature higher than the temperature of the beginning of the glass transition zone. At this temperature the soft segments become enough flexible to have this switch function.

It is usually common to consider shape memory effect (SME) as macroscopic and visual shape changes. However, this effect may be observed also in certain cases when the shape change is in a microscopic scale. For example, in the following cases, one can see the effect of shape memory: 
- Elasticity is a reversible phenomenon. In an elastic zone, the deformation is generally small and the shape (volume) change of the sample may be in microscopic scale. This change depends on the strain and Poisson's ratio. Releasing the specimen in this zone, without any external stimulation, it regains its initial shape.

- Shrinkage is also another phenomenon illustrating SME. In the case of semicrystalline polymers, shrinkage is usually observed at the end of molding, when the molten polymer is crystallized by cooling. The microchange in dimensions of the sample during the time after the injection molding cycle can be considered as recovery and regain the permanent shape.

- Polymers may absorb water. The water may fill the free volume of the molecular structure and push on the molecular chains. The change of volume is microscopic. The water absorption capacity of a polymer depends on diffusion and solubility coefficients. ${ }^{14,15}$ The result is the swelling and microscopic volume expansion. Drying the sample, water goes out and the sample regains its initial form.

- The dimensions of a specimen may also change by thermal stimulation. In fact, when the sample is heated the amplitude of molecular motion increases, increasing the average molecular distance. The thermal expansion coefficient of polymers ${ }^{16}$ depends on the physical state of the polymer. In the rubbery state this coefficient is more important than in the glassy state.

In all of these examples, the microchange of the shape (volume) has an important effect on the microstructure and properties of the polymer. For SMPs, this microchange of the shape may be reversible; whereas, the modification of microstructure may be irreversible. The "micro-SME" is referred to as the reversibility of these microchanges of the shape.

It is possible to fix the microchange of the shape by gaining a temporary shape to the polymer. The sample then, in the next step, regains its initial volume by stimulation; but it is not sure that it can regain its initial properties. So in the study of SME, one of the major questions is about the relation between SME and properties memory effect.

In this article, we try to explain the mechanism of SME of polyurethane. Using a biparabolic model, we will show that the polymer after recovery does not keep the same properties as the initial polymer. This phenomenon also will be verified by tensile tests successively performed on the same sample.

\section{MATERIALS AND METHODS}

\section{Materials}

The polymer used for this study is a polyurethane supplied by the RAIGI Company. This polymer is the result of the reaction between an isocyanate and a polyol. The isocyanate is diphenylmethane diisocyanate (MDI) with a functionality of more than two. The polyol is a polyester with molecular weight of $800 \mathrm{~g} / \mathrm{mol}$. The ratio of $\mathrm{NCO} / \mathrm{OH}$ is equal to 19.8. This polyol is then mixed with another polyol (PES4), chain extender, with a molecular weight of $400 \mathrm{~g} / \mathrm{mol}$. Catalysts of the type of aluminosilicate and diamine have been used for the reactions. The result of this

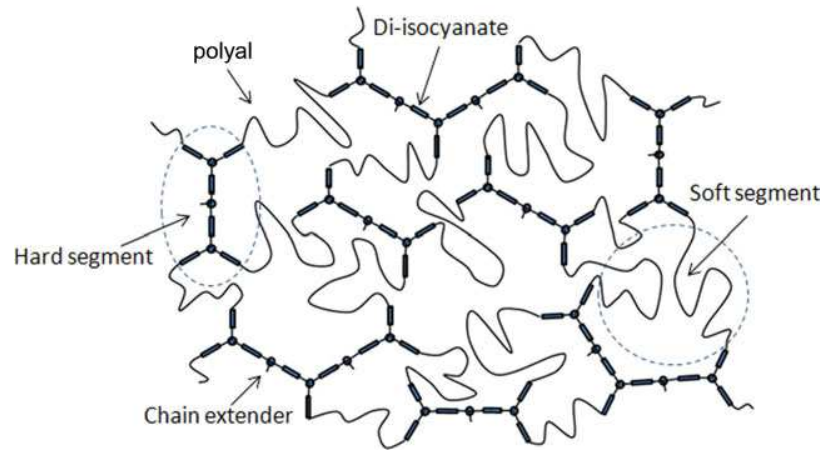

Figure 1. Presentation of PU structure in 2D. [Color figure can be viewed in the online issue, which is available at wileyonlinelibrary.com.]

polymerization is a thermoset presenting crosslinked network as shown in Figure 1.

The reactive mixture has been injected in the mould in order to prepare the samples for tensile, stress-relaxation, and recovery tests. The mould was then heated and the solid sample after reactions between different components of mixture has been demoulded.

DMTA tests have been also realized in order to characterize the polymer, to model its viscoelastic properties and to compare its behavior at different steps of shape memory tests.

\section{Methods}

Differential Scanning Calorimetric Test (DSC). The measures are carried out with the DSC Q10 V9.0 Build275 (TA Instruments). The samples of a mass between $10 \mathrm{mg}$ and $20 \mathrm{mg}$ are placed in hermetic aluminum capsules. The sample was heated first up to $120^{\circ} \mathrm{C}$ with a temperature rate of $5^{\circ} \mathrm{C} / \mathrm{min}$, in order to eliminate the effect of thermal history of the material. It was cooled down to $0^{\circ} \mathrm{C}$ in order to be reheated up to $100^{\circ} \mathrm{C}$ with the same temperature rate. The result shows a glass transition temperature of $32^{\circ} \mathrm{C}$ in the zone of 17 and $47^{\circ} \mathrm{C}$.

Dynamical Mechanical Thermal Analysis (DMTA). For the modeling and characterization of the viscoelastic behavior of polyurethane, the tests were carried out in dual cantilever using a DMA 242 instrument (from Netzsch Company). These tests were performed under the following condition: Frequency $1 \mathrm{~Hz}$, temperature ranging from -100 to $100^{\circ} \mathrm{C}$, temperature rate $2^{\circ} \mathrm{C} / \mathrm{min}$, strain amplitude $30 \mu \mathrm{m}$, and dynamic force $1 \mathrm{~N}$.

The sample (with $25 \times 4 \times 2 \mathrm{~mm}^{3}$ as dimensions) has been taken from the rectangular part of the demoulded specimen.

Figure 2 shows the variations of $G$ and $G^{\prime \prime}$ versus temperature. The spectrum of $G^{\prime \prime}$ shows a $T_{\alpha}$ of almost $37^{\circ} \mathrm{C}$ and a $T_{\beta}$ of $-80^{\circ} \mathrm{C}$ for polyurethane under study.

As it can be also observed, the value of storage modulus in glassy state is 3 orders of magnitude higher than that in its rubbery state. This important difference of modulus between glassy and rubbery state may explain the shape memory capacity of the crosslinked polyurethane under study.

Shape Memory Test. The tests were carried out in different steps using different techniques: tensile test, stress-relaxation test, and recovery test. 


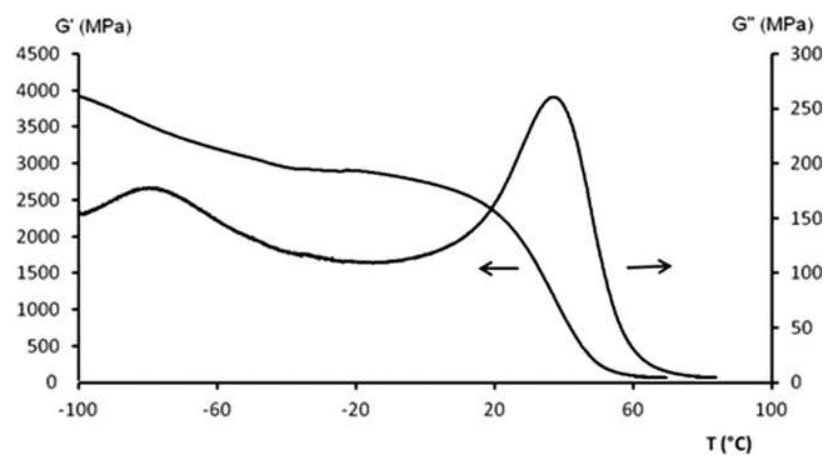

Figure 2. DMTA spectra of polyurethane.

Tensile test. Tensile tests have been achieved with the Instron 4502 (loading cell of $1 \mathrm{kN}$ ) according to the standard NF ISO 6239. The strain rate is $20 \mathrm{~mm} / \mathrm{min}$. This machine is equipped with a temperature controlled thermo chamber for heating the samples and performing the tests at different temperatures. The dimensions of the samples were: length $75 \mathrm{~mm}$, length of rectangular part $25 \mathrm{~mm}$, width $4 \mathrm{~mm}$, and thickness $2 \mathrm{~mm}$.

By using tensile test, the samples have been deformed by up to $100 \%$ at a temperature chosen in glass transition zone or higher. By cooling the sample, of the $100 \%$ strain has been conserved in the sample (fixing).

Stress-Relaxation test. This test has been performed at the end of the tensile test with the same tensile test machine. The strain has been taken constant $(100 \%)$ and the decrease of stress has been measured against the time. This test has been performed to eliminate the residual stresses induced during the tensile test in the samples. The stress-relaxation tests have been performed at different temperatures, in the range between 30 and $60^{\circ} \mathrm{C}$.

Recovery test. Using DMTA equipment, this test has been realized on the samples after tensile and stress-relaxation test and after fixing $100 \%$ strain by cooling, at the temperatures higher than the beginning of the glass transition zone. It is indeed an isothermal creep test under zero stress on the stretched (100\%) samples after relaxation. To study the effect of temperature on the rate of recovery, different tests have been performed at different temperatures in the range between 30 and $60^{\circ} \mathrm{C}$.

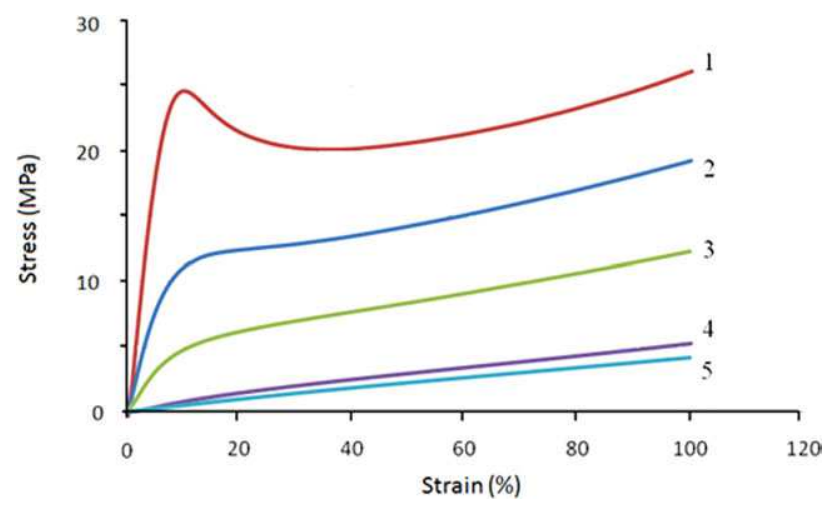

Figure 3. Tensile tests on polyurethane samples at: (1) $30^{\circ} \mathrm{C}$, (2) $35^{\circ} \mathrm{C}$, (3) $40^{\circ} \mathrm{C}$, (4) $50^{\circ} \mathrm{C}$, and (5) $60^{\circ} \mathrm{C}$. [Color figure can be viewed in the online issue, which is available at wileyonlinelibrary.com.]
Each set of test (tensile, stress-relaxation and recovery) have been performed on the same sample at the same temperature.

\section{RESULTS}

Tensile Tests

The results of the tensile tests on polyurethane samples at different temperatures are presented in Figure 3. These results show clearly the influence of temperature on the mechanical properties of polyurethane. The test at $30^{\circ} \mathrm{C}$ presents yield point $\left(\boldsymbol{\varepsilon}_{\mathrm{y}}=\right.$ $10 \%$ and $\sigma_{\mathrm{y}}=25 \mathrm{MPa}$ ), which separates viscoelastic zone from viscoelastoplastic region. This yield point disappears for the test at temperatures higher than $35^{\circ} \mathrm{C}$.

All samples have been stretched by up to $100 \%$ deformation. This relatively high strain means that the sample has been brought into the viscoelastoplastic deformation zone in order to change significantly the shape of the sample. The energy of deformation may be stored in the structure of the polymer. By thermal stimulation, this energy will be released, providing the driving force to bring the sample to its original shape.

The results also show that the Young modulus and the stress at $100 \%$ deformation decrease by increasing the temperature.

\section{Relaxation}

Stress-relaxation tests have been performed at different temperatures from 30 to $60^{\circ} \mathrm{C}$ (Figure 4). These tests have been performed at the end of tensile tests on the samples after $100 \%$ of deformation.

The results show the temperature dependence of relaxation phenomenon. The relaxation rate is very high at $60^{\circ} \mathrm{C}$; it is very low at $30^{\circ} \mathrm{C}$. The curve reaches to a stationary state only after few minutes at $60^{\circ} \mathrm{C}$; whereas it does not reach an equilibrium state after $2 \mathrm{~h}$ of stress-relaxation test at $30^{\circ} \mathrm{C}$.

In all cases, the relaxation does not lead the sample to zero stress. It seems the stress-relaxation curves at different temperatures tend to the same stress level. The result at $60^{\circ} \mathrm{C}$ shows that the value of this stress is about $4.7 \mathrm{MPa}$. This stress remains in the sample and it seems that it is the origin of the

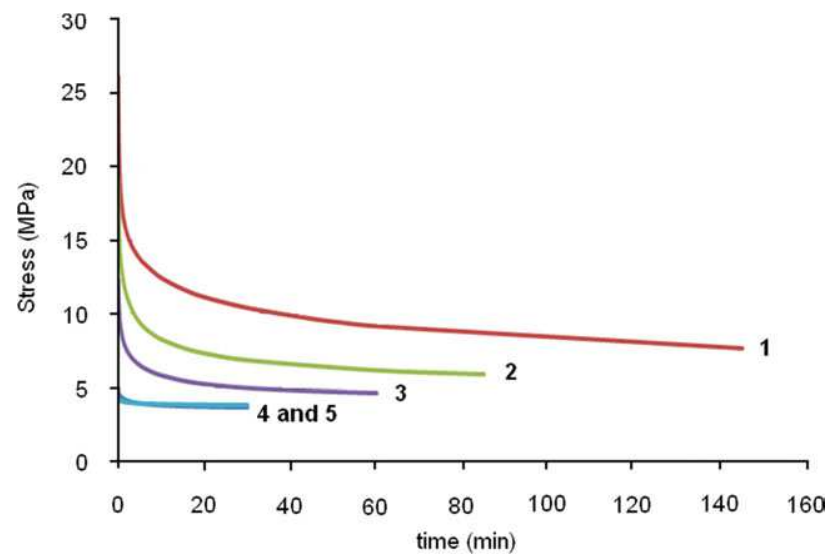

Figure 4. Stress-relaxation tests (constant deformation $=100 \%$ ) on polyurethane samples at: (1) $30^{\circ} \mathrm{C}$, (2) $35^{\circ} \mathrm{C}$, (3) $40^{\circ} \mathrm{C}$, (4) $50^{\circ} \mathrm{C}$ and (5) $60^{\circ} \mathrm{C}$. [Color figure can be viewed in the online issue, which is available at wileyonlinelibrary.com.] 


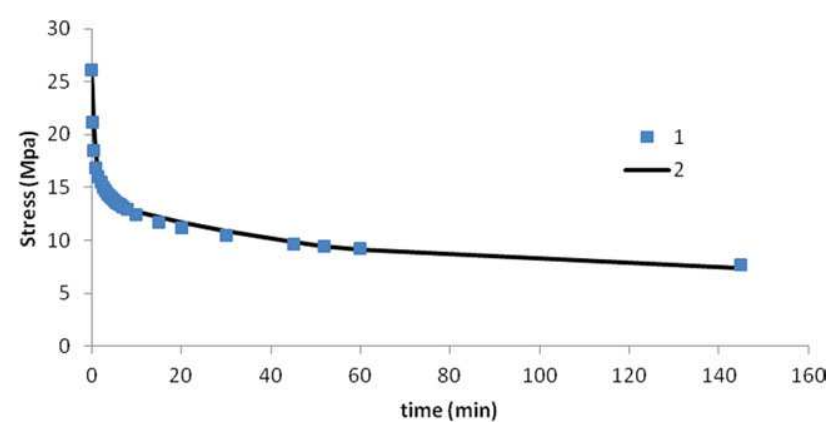

Figure 5. Stress-relaxation test on $\mathrm{PU}$ specimen at $30^{\circ} \mathrm{C}$ : Experimental results (1), Modified Maxwell-Weichert model (2). [Color figure can be viewed in the online issue, which is available at wileyonlinelibrary.com.]

driving force, which brings the sample to its original shape during the recovery test.

To study the stress-relaxation phenomenon, several authors have used different rheological models. ${ }^{17-22}$ In the "MaxwellWeichert" model ${ }^{21}$ a set of Maxwell units (with different modulus, viscosity and relaxation time) are combined together in parallel. The "Maxwell-Weichert" model also has been simplified by a combination of two Maxwell unites in parallel with one spring. ${ }^{22,23}$ This model may be presented by the following equation indicating the variation of $\sigma$ versus time during stressrelaxation test:

$$
\sigma(t)=E_{1} \varepsilon_{0} \exp \left(-\frac{t}{\tau_{1}}\right)+E_{2} \varepsilon_{0} \exp \left(-\frac{t}{\tau_{2}}\right)+\varepsilon_{0} E_{3}
$$

Where, $\tau_{1}$ and $\tau_{2}$ are the relaxation times.

This model was used to represent the relaxation behavior of polyurethane at $30^{\circ} \mathrm{C}$. The model was then compared with the experimental data (Figure 5). As it can be shown, there is a good concordance between the model and the experimental curve obtained at $30^{\circ} \mathrm{C}$.

This modeling then may give the following information:

$$
\begin{aligned}
& \sigma_{1}=\mathrm{E}_{1} \cdot \varepsilon_{0}=12 \mathrm{MPa} \text { related to the hard segment, } \\
& \sigma_{2}=\mathrm{E}_{2} \cdot \varepsilon_{0}=7 \mathrm{MPa} \text { related to the soft segment, } \\
& \sigma_{3}=\mathrm{E}_{3} \cdot \varepsilon_{0}=7 \mathrm{MPa} \text { related to the pure elastic part, } \\
& \tau_{1}=1 \mathrm{~s}, \text { and } \tau_{2}=40 \mathrm{~s}
\end{aligned}
$$

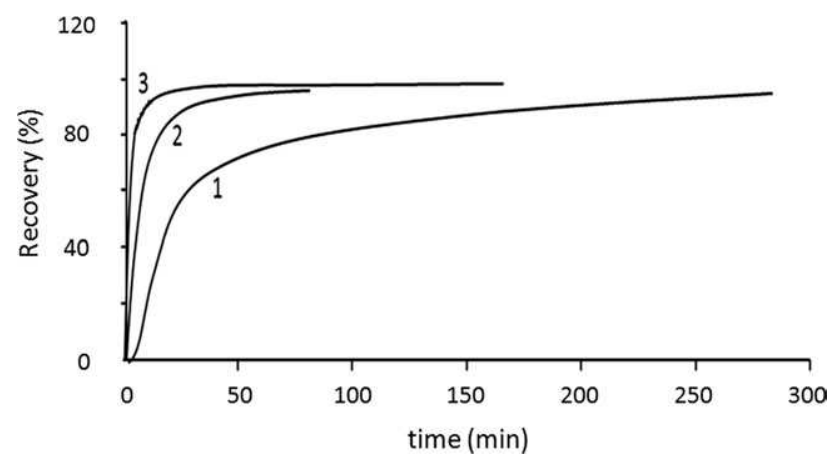

\begin{tabular}{|c|c|c|}
\hline Temperature $\left({ }^{\circ} \mathrm{C}\right)$ & $R_{\text {red }} / \mathrm{s}$ & $\begin{array}{l}t_{\text {rec }}(100 \%), \\
\text { (min) }\end{array}$ \\
\hline 40 & 3.6 & 353 \\
\hline 50 & 9.9 & 82 \\
\hline 60 & 26.1 & 35 \\
\hline Apparent activation energy & $-86 \mathrm{~kJ}$ & $100 \mathrm{~kJ}$ \\
\hline
\end{tabular}

Figure 6. Isothermal recovery tests at different temperatures at (1) $40^{\circ} \mathrm{C}$, (2) $50^{\circ} \mathrm{C}$, and $(3) 60^{\circ} \mathrm{C}$.
Table I. The Temperature Dependence of Rate of Recovery and Time for $100 \%$ Recovery

This result may give us information about the behavior of hard and soft segments of our polymer.

\section{Recovery}

The recovery tests at different temperatures have been performed after stress-relaxation tests (Figure 6). The results show that the recovery rate (slope of tangent at beginning of the curve), $R_{\mathrm{rec}}$ is strongly influenced by temperature. At $60^{\circ} \mathrm{C}$, for example, the sample regains $80 \%$ of its initial shape after $2.5 \mathrm{~min}$; while at $40^{\circ} \mathrm{C}, 85 \mathrm{~min}$ is needed for the same recovery. Table I shows the temperature dependence of recovery rate and the regaining time of initial shape, $t_{\mathrm{rec}}(100 \%)$. The temperature dependence of $R_{\mathrm{rec}}$ and $t_{\mathrm{rec}},(100 \%)$ may be verified by Arrhenius model.

$$
R_{\mathrm{rec}}=R_{\mathrm{rec} 0} \exp \left[\frac{\left(E_{\mathrm{ap}}\right)_{R_{\mathrm{rec}}}}{R \cdot T}\right] \text { and } t_{\mathrm{rec}}=t_{\mathrm{rec} 0} \exp \left[\frac{\left(E_{\mathrm{ap}}\right)_{t_{\mathrm{rec}}}}{R \cdot T}\right]
$$

where

$\left(E_{\mathrm{ap}}\right)_{R_{\mathrm{rec}}}=$ apparent activation energy related to $R_{\mathrm{rec}}$,

$\left(E_{\text {ap }}\right)_{t_{\text {rec }}}=$ apparent activation energy related to $t_{\text {rec }}$,

$R_{\text {rec } 0}$ and $t_{\text {rec } 0}=$ constants.

By linear regression, the apparent activation energy has been determined: about $100 \mathrm{~kJ}$ for $t_{\mathrm{rec}}(100 \%)$, and $-86 \mathrm{~kJ}$ for $R_{\mathrm{rec}}$.

To present the different steps of shape memory tests and their interdependence, a tridimensional presentation of these results at $30^{\circ} \mathrm{C}$ has been shown in Figure 7.

\section{Thermodynamic Behavior}

DMTA tests have been performed on samples at its different steps of shape memory tests: on virgin (nonstretched) sample, and on the samples before (stretched) and after recovery tests.

i. Comparing the thermodynamic behavior of the stretched and nonstretched sample of SMPs (Figure 8) helps to find the relationship between SME and viscoelastic properties of polymer. In fact, by increasing the temperature, the molecular motion becomes more and more important. The test on stretched sample is especially interesting because, in the glass transition zone, the polymer tries to regain its initial shape. This situation permits to correlate the SME and the viscoelastic properties.

ii. The comparison of the DMTA spectrum of the sample before and after the recovery test (Figure 9) reveals that $T_{\mathrm{g}}$ of the sample decreases during the recovery test. Before the recovery test, $T_{\mathrm{g}}$ is about $42.5^{\circ} \mathrm{C}$ after recovery test it becomes $40^{\circ} \mathrm{C}$. Indeed before the recovery test, the sample 


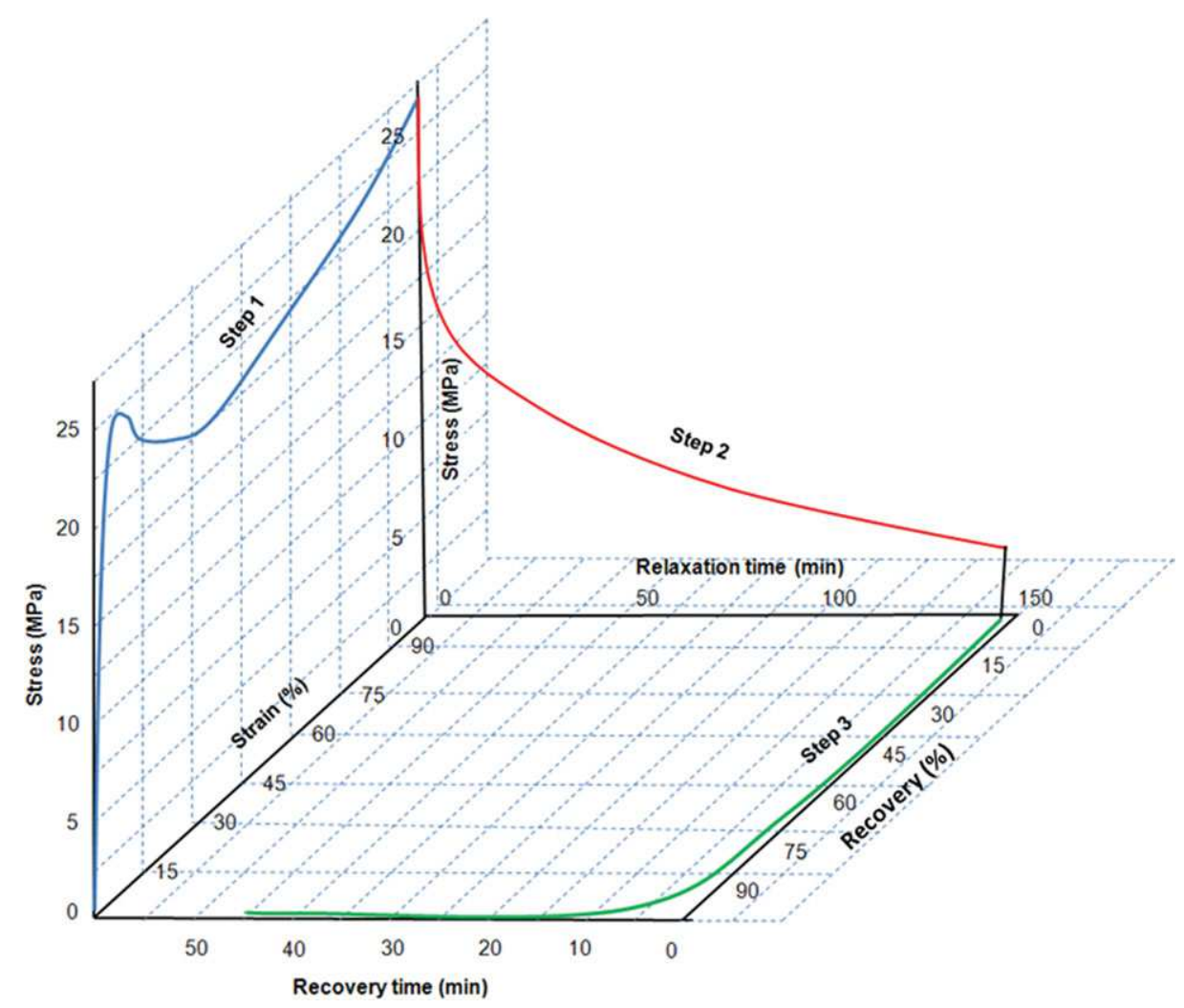

Figure 7. Shape memory effect of crosslinked polyurethane. step (1) Stress-strain curve; step (2) relaxation test, and step (3) recovery test. [Color figure can be viewed in the online issue, which is available at wileyonlinelibrary.com.]

is stretched and this stretching decreases the molecular mobility. If we compare the sample after recovery test with the virgin one, we see clearly that the sample even recovering its original shape, does not regain totally its original properties; knowing that the $T_{\mathrm{g}}$ of the virgin polymer (determined with the same method) is about $37^{\circ} \mathrm{C}$, lower than the recovered sample.

The difference of $G^{\prime}$ and $G^{\prime \prime}$ of the samples before and after recovery tests is related to the SME. In fact, the recovery test shows the sample tries to obtain its virgin properties. Figure 10 shows the variation of difference of $G^{\prime}$ (and $G^{\prime \prime}$ ) before and after recovery test. This variation can be considered as derivative of $G$ (or $G^{\prime \prime}$ ) related to the SME. We call it "apparent recovery rate." Therefore, the following comments:

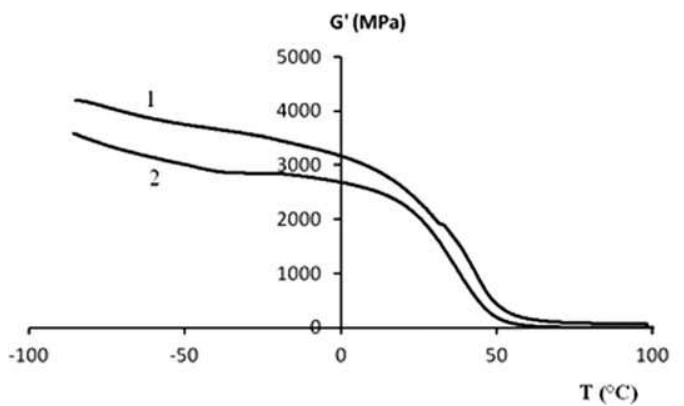

- In $\alpha$ transition zone, for $T<40^{\circ} \mathrm{C}$, "apparent recovery rate" related to $G$ is an increasing function of temperature; for $T$ $>40^{\circ} \mathrm{C}$, it decreases by temperature.

- Concerning $G$ ", there is practically no change of the "apparent recovery rate" at glassy and rubbery states.

- Like elasticity, the variation of loss modulus is significant in $\alpha$ transition zone, and presents a pic at $48.5^{\circ} \mathrm{C}$. Below this pic, "apparent recovery rate" related to $G$ " is positive and above this temperature, it is negative.

\section{Modeling}

Different approaches have been used to study the viscoelastic properties in the temperature range between glassy and rubbery domain $^{23}$ and different models have been proposed to predict these properties. These models generally represent the curve of

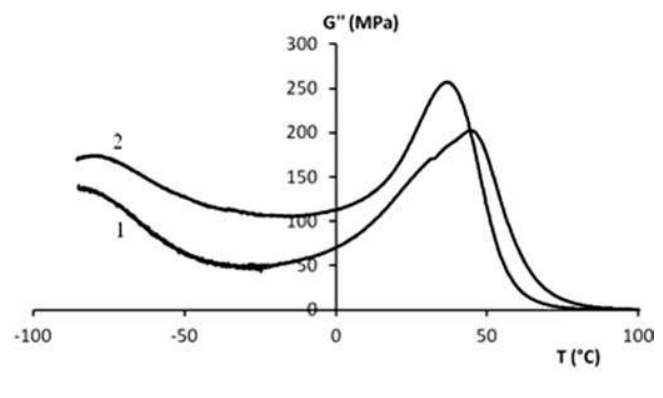

Figure 8. DMTA spectra of stretched (1) and nonstretched (2) samples. 

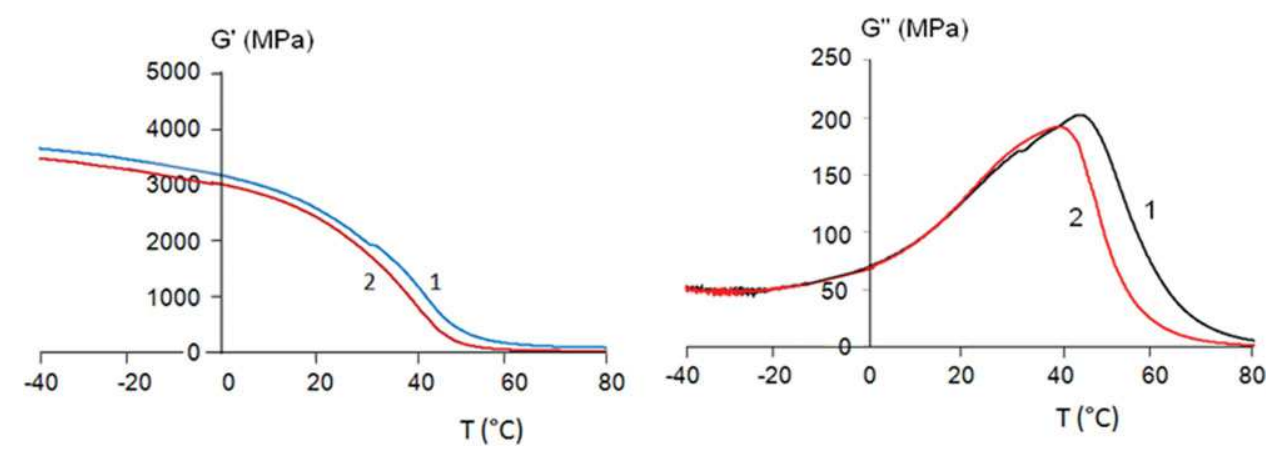

Figure 9. DMTA curves of PU samples: (1) before recovery, (2) after recovery. [Color figure can be viewed in the online issue, which is available at wileyonlinelibrary.com.]

$G^{\prime \prime}$ (loss modulus) versus $G^{\prime}$ (storage modulus) and is called the COLE-COLE diagram. ${ }^{24}$ The theoretical model must be validated by the experimental data obtained by the dynamic mechanical thermal analysis (DMTA) tests.

After DMTA tests, COLE-COLE diagram has been plotted for each sample. These results (Figures 8, 9, and 10) show an asymmetric COLE-COLE diagram for all the samples.

According to Perez, ${ }^{25}$ the behavior of amorphous polymers (thermoset polyurethane for example) can be explained by biparabolic model presented by following equation:

$$
G^{*}=G_{0}+\frac{G_{\infty}-G_{0}}{1+(i \omega \tau)^{-\kappa}+Q(i \omega \tau)^{-\kappa^{\prime}}}
$$

Where $\kappa, \kappa^{2}$, and $Q$ are the constants of this model. $\omega=2 \pi \mathrm{f}$ is the angular frequency $(f=$ frequency)

$G^{*}$ is the complex shear modulus: $G_{\infty}$ and $G_{0}$ are the value of shear modulus at the respective glassy state and rubbery state. $\kappa$ at $\kappa$ ' depending on the slope of the tangents at the beginning and at the end of the COLE-COLE diagram, $Q$ is a constant related to the maximum value of $G^{\prime \prime} . \tau$ is the average relaxation time.

The real and imaginary parts of $G^{\star}$ [eq. (2)], $G$, and $G^{\prime}$ then may be determined by the following equations:

$$
G^{\prime}=G_{0}+\left(G_{\infty}-G_{0)} \frac{1+\cos \left(-\frac{\pi}{2} k\right)(\omega \tau)^{-\kappa}+Q \cos \left(-\frac{\pi}{2} k^{\prime}\right)(\omega \tau)^{-\kappa^{\prime}}}{D}\right.
$$

$$
G^{\prime \prime}=-\left(G_{\infty}-G_{0}\right) \frac{\sin \left(-\frac{\pi}{2} k\right)(\omega \tau)^{-\kappa}+Q \sin \left(-\frac{\pi}{2} k^{\prime}\right)(\omega \tau)^{-\kappa^{\prime}}}{D}
$$

with

$$
\begin{aligned}
D= & {\left[1+\cos \left(-\frac{\pi}{2} k\right)(\omega \tau)^{-\kappa}+Q \cos \left(-\frac{\pi}{2} k^{\prime}\right)(\omega \tau)^{-\kappa^{\prime}}\right]^{2} } \\
& +\left[\sin \left(-\frac{\pi}{2} k\right)(\omega \tau)^{-\kappa}+Q \sin \left(-\frac{\pi}{2} k^{\prime}\right)(\omega \tau)^{-\kappa^{\prime}}\right]^{2}
\end{aligned}
$$

A numerical method allows the plotting of the theoretical COLE-COLE diagram in order to fit it on the experimental curve. The results of modeling are shown in Figures 11, 12, and 13.

These results call the following comments:

i. In the zone of the glass transition temperature in which the polymer shows its SME, the viscoelastic behavior cannot be presented by generalized Maxwell or "Maxwell-Weichert" model, contrary to what was proposed by several authors. ${ }^{17-22}$ In fact, the COLE-COLE diagram relating to this model is a segment of the circle. This is why we have chosen the biparabolic model, which shows an asymmetric COLE-COLE diagram.

ii. In all the three cases, the theoretical curve fits perfectly on the experimental results, signifying that the biparabolic model can accurately predict the viscoelastic behavior of PU under study.

iii. It must be noted that this modeling does not show the viscoelastic behavior of polymer at temperatures below $T_{\beta}$
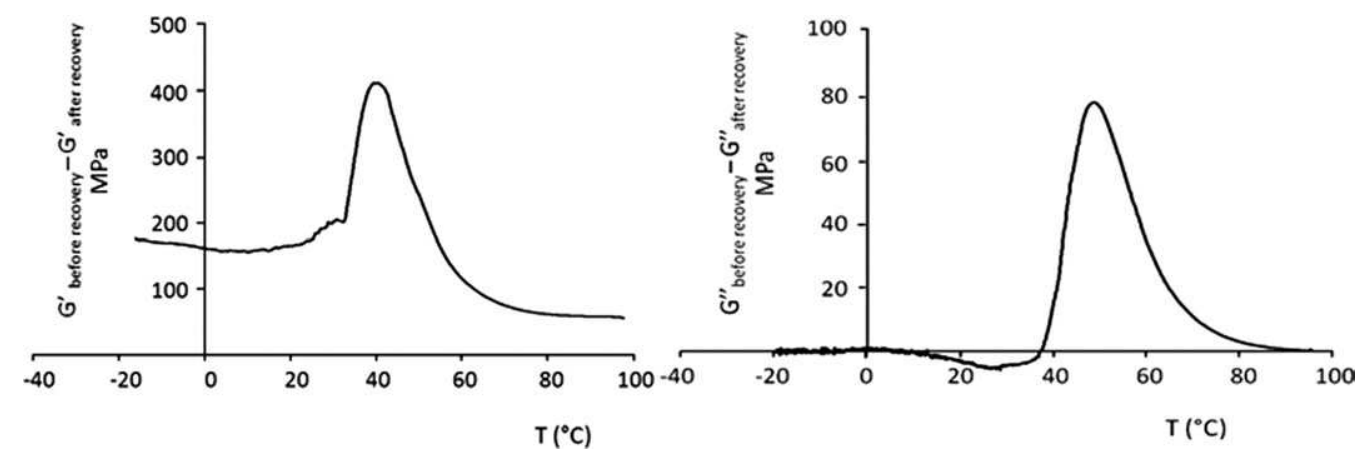

Figure 10. Apparente recovery rate related to $G^{\prime}$ and $G^{\prime \prime}$ versus temperature. 


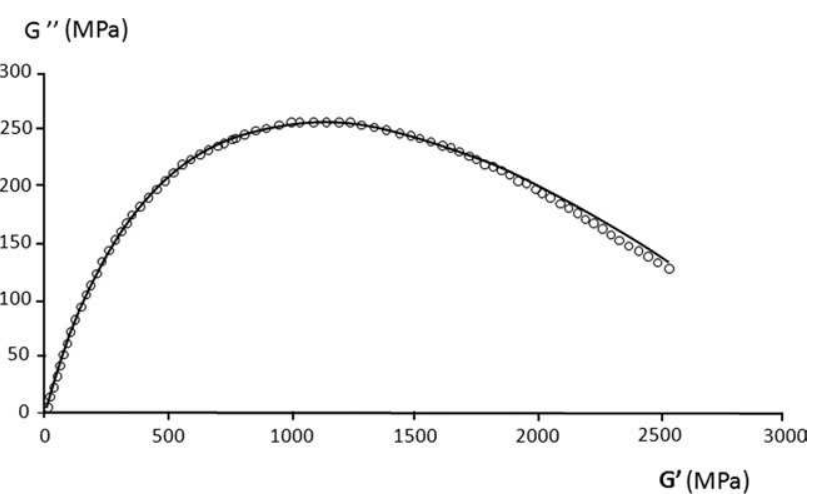

Figure 11. COLE-COLE diagram of virgin PU (before tensile test). Experimental data $(\bigcirc)$, Biparabolic model (solid curve).

due to the lack of good results. As it can be observed, the experimental curve does not have the second intersection with $x$-axis.

iv. COLE-COLE diagram of virgin (nonstretched) and stretched samples are presented in Figure 14. As it can be seen, the COLE-COLE diagram may be divided in three different zones:

- Zone I $\left(T>55^{\circ} \mathrm{C}\right)$ corresponds to the rubbery state. In this zone, stretched and nonstretched samples have almost the same form. Because in this zone the temperature is higher than the glass transition temperature so the stretched relaxed sample regains its initial shape during the test and obtains the same behavior as the nonstretched sample; however, the storage modulus of the stretched sample is always higher than that of the nonstretched one.

- Zone II (between 0 and $55^{\circ} \mathrm{C}$ ) is related to the glass transition region. In this zone, the storage modulus decreases sharply by increasing the temperature. However, at each temperature, the loss modulus of the nonstretched sample is higher than that of the stretched one. Indeed, the amplitude of molecular mobility decreases because of stretching.

- Zone III $\left(T<0^{\circ} \mathrm{C}\right)$ is the zone of the glassy state. In this zone, the molecular motions are at a very low level. In the glassy state, between $-85^{\circ} \mathrm{C}\left(T_{\beta}\right)$ and $0^{\circ} \mathrm{C}$ (onset of storage modulus), this motion corresponds to the movement

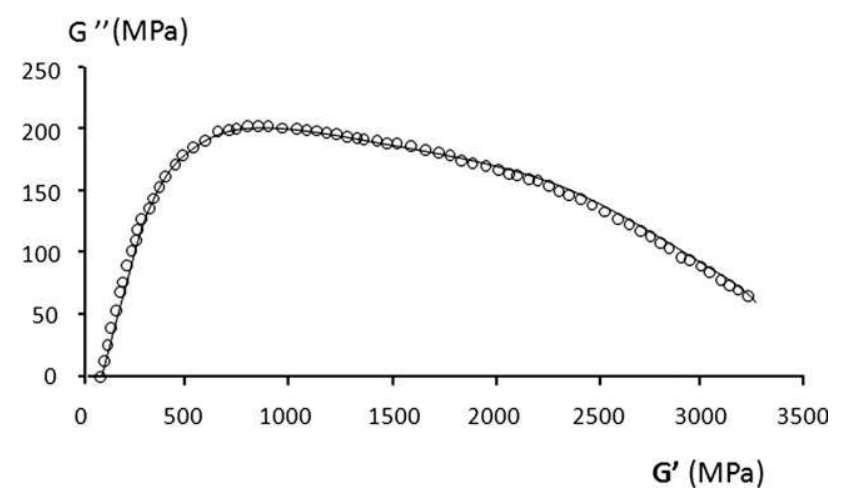

Figure 12. COLE-COLE diagram of PU sample after relaxation and before recovery test. Experimental data $(\bigcirc)$, biparabolic model (solid curve).

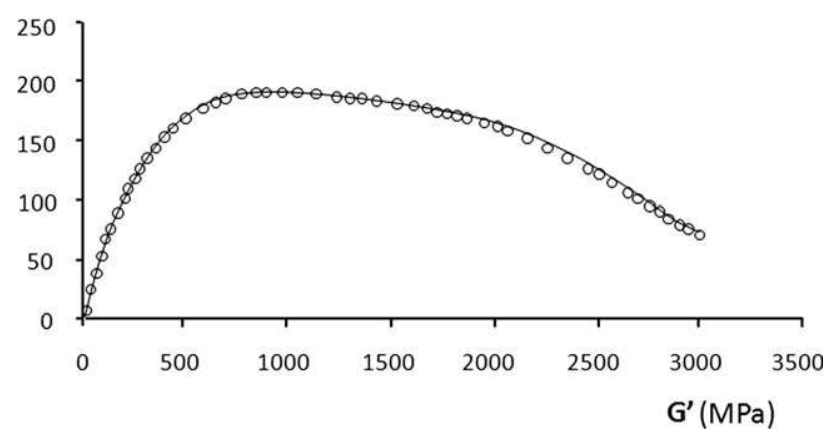

Figure 13. COLE-COLE diagram of PU sample after recovery test. Experimental data $(\bigcirc)$, biparabolic model (solid curve).

of small segment (a few carbon atoms) of molecular chain. The storage modulus of the stretched sample is significantly higher than that of the nonstretched one because as mentioned before, stretching decreases the molecular motion and increases the molecular interaction forces.

v. Table II compares the parameters of COLE-COLE diagram of a virgin PU sample (nonstretched) and PU samples before and after recovery tests. It could be seen that $G_{\infty}$ and $G_{0}$ are not the same. These constants have increased after tensile and relaxation tests. $G_{\infty}$ changes from $3150 \mathrm{MPa}$ to $3450 \mathrm{MPa}$ and $G_{0}$ from $12 \mathrm{MPa}$ to $75 \mathrm{MPa}$. After recovery test, $G_{\infty}$ decreases from $3450 \mathrm{MPa}$ to $3300 \mathrm{MPa}$.

vi. During the numerical application, it was seen that a very small change of the constants $(\kappa, \kappa$, and $Q)$ leads to noticeable modifications of the shape of the COLE-COLE diagram. So we can say that during shape memory tests the variations of $\kappa, \kappa^{\prime}, Q$, are significant.

Indeed $\kappa$ and $\kappa$ ' are related to the molecular mobility and $Q$ is a function of the concentration of defects. It is related to the maximum value of $G^{\prime \prime}$, which is higher (the lower is $Q^{25}$ ).

It can be seen that the value of these constants, especially, $\kappa^{\prime}$ and $Q$ are not the same for different samples.

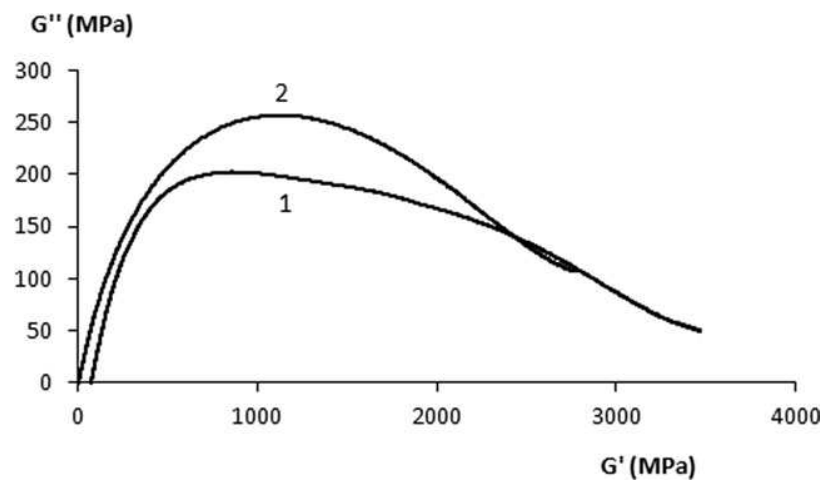

Figure 14. COLE-COLE diagram of stretched (1) and nonstretched (2) samples. 
Table II. The Values of Different Parameters of Biparabolic Model for the Samples at Different States of Shape Memory Tests

\begin{tabular}{llllll}
\hline Samples & $\begin{array}{l}G_{0} \\
(\mathrm{MPa})\end{array}$ & $\begin{array}{l}G_{\infty} \\
(\mathrm{MPa})\end{array}$ & $\kappa$ & $\kappa^{\prime}$ & $\mathrm{Q}$ \\
\hline Virgin sample & 12 & 3150 & 0.47 & 0.16 & 2.00 \\
Before recovery test & 75 & 3450 & 0.45 & 0.128 & 2.73 \\
After recovery test & 18 & 3300 & 0.46 & 0.132 & 2.85 \\
\hline
\end{tabular}

\section{Properties Memory Effect}

Figure 15 compares the storage (elastic) modulus of the sample in two steps of the shape memory tests, initial state (before tensile test) and after recovery tests. It can be seen that after recovery test (curve 2) and even regaining 100\% of the initial shape, the sample does not show the same properties and its storage modulus spectrum is different (curve 1). Especially, in glassy zone (low temperatures) this difference is more important than in rubbery state (higher temperatures). Because of the importance of this result and in order to be sure about the accuracy of this result, the shape memory tests (tensile test, stress-relaxation test, fixing, and recovery tests) have been performed on two more samples and then DMTA experiment carried out on the recovered samples. The same tendency has been observed. It was seen that, $G^{\prime}$ and $G^{\prime \prime}$ of recovered and virgin samples are different with different alpha transition temperature.

The same result can be shown also in Table II. The value of constants is not the same for the virgin sample and for the sample after recovery test.

The difference between virgin and stretched samples, as has been explained before, can be related to the molecular mobility and variation of concentration of defects during the tensile and relaxation tests. But it is more difficult to understand why these constants are not the same for initial sample and the sample after recovery test when it has regained its initial shape.

This result is particularly important in the study of SMPs. In fact, practically all studies in this field have shown their interest about the SME. In these studies, the authors try to explain the mechanism of SME by the results obtained from different experiments dedicated to the determination of different proper-

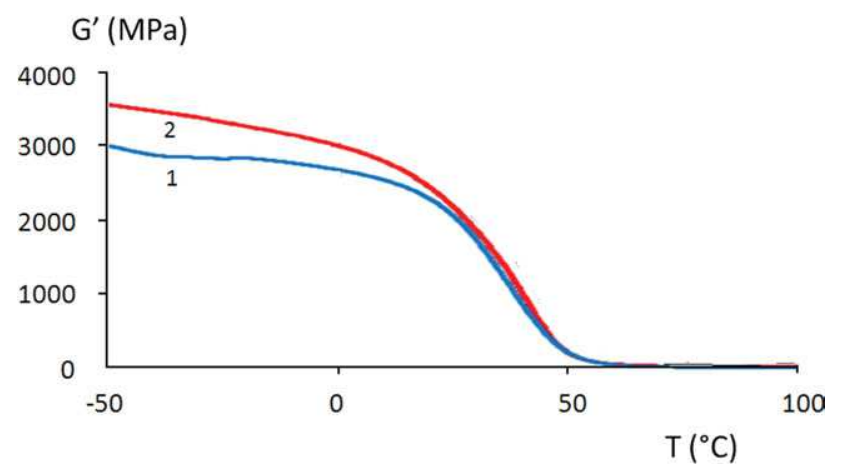

Figure 15. Elastic modulus versus temperature for two samples: (1) virgin sample, (2) after recovery test. [Color figure can be viewed in the online issue, which is available at wileyonlinelibrary.com.]

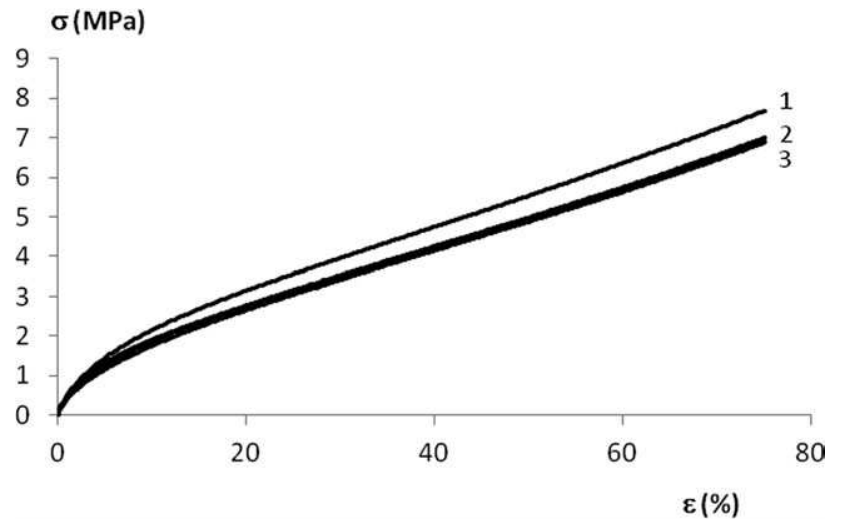

Figure 16. Stress-strain curves obtained by tensile tests at $60^{\circ} \mathrm{C}$, during successive cycles of shape memory tests at $60^{\circ} \mathrm{C}$ (1) virgin polymer, (2) after recovery test of first cycle, (3) after recovery test of second cycle.

ties (physical, viscoelastic, and so on). But the question here is, has a shape memory polymer also properties memory effect? That means after deformation and change of properties, does it remember its initial properties? The results of DMTA tests and the modeling based on these results gave a negative answer to this question. They have shown that the shape memory polymer even regaining $100 \%$ of initial shape does not always present the same properties as virgin polymer. To verify this idea, three successive cycles of shape memory tests have been performed on the same sample (Figure 16). The dimensions and the weight of the sample have been measured for different cycles before and after the tensile and recovery tests (Table III).

One can observe that the sample regained $100 \%$ of its initial shape form at the end of each cycle. The weight of the sample also did not change, indicating that the sample did not absorb the humidity and the change of mechanical properties does not depend on water absorption.

However, the results clearly show that the Young modulus and stress at $75 \%$ of strain are not the same for virgin and recovered polymer. Initially, the Young modulus of the sample at $60^{\circ} \mathrm{C}$ is about $41.5 \mathrm{MPa}$. After recovery test of the first cycle, the Young modulus of the sample becomes about $34.5 \mathrm{MPa}$ at $60^{\circ} \mathrm{C}$. The same results have been obtained for stress at $75 \%$ of deformation at $60^{\circ} \mathrm{C}$; first cycle: $7.7 \mathrm{MPa}$, second cycle: 7.0 $\mathrm{MPa}$, and third cycle: $6.8 \mathrm{MPa}$. These successive cycles of shape memory tests have been performed on two more samples. In all the cases the same tendency has been observed.

Another set of successive shape memory tests has been realized on the same sample and the tensile test has been performed at $35^{\circ} \mathrm{C}$ on the $100 \%$ recovered samples (Figure 17 ).

Young modulus and stress at $100 \%$ of deformation have been measured (Table IV). The results reinforce the idea that even obtaining the initial shape, the sample does not regain totally its initial properties.

How this phenomenon can be explained?

It has been shown before (Figure 4; curves 4 and 5) that even at the end of the stress-relaxation test (on the 100\% stretched 
Table III. Dimensions and Properties (Young Modulus and Stress at $75 \%$ of Strain) Change During Successive Cycles of Shape Memory Tests at $60^{\circ} \mathrm{C}$

\begin{tabular}{|c|c|c|c|c|c|c|c|}
\hline No. of cycle & Different tests & $\begin{array}{l}\text { Length } \\
\text { (mm) }\end{array}$ & $\begin{array}{l}\text { Width } \\
(\mathrm{mm})\end{array}$ & $\begin{array}{l}\text { Thickness } \\
(\mathrm{mm})\end{array}$ & Weight (g) & $\begin{array}{l}\text { Stress at } 75 \% \\
\text { of strain (MPa) }\end{array}$ & $\begin{array}{l}\text { Modulus } \\
\text { (MPa) }\end{array}$ \\
\hline \multirow[t]{4}{*}{1} & Before tensile test & 74.62 & 4.02 & 2.98 & 2.2940 & 7.7 & 41.5 \\
\hline & After tensile test & 93.16 & 3.18 & 2.38 & & & \\
\hline & Before recovery test & 93.07 & 3.18 & 2.40 & & & \\
\hline & After recovery test & 74.60 & 3.98 & 2.98 & 2.2938 & & \\
\hline \multirow[t]{3}{*}{2} & After tensile test & 94.06 & 3.20 & 2.42 & 2.2938 & 7.0 & 34.5 \\
\hline & Before recovery test & 93.88 & 3.21 & 2.43 & & & \\
\hline & After recovery test & 74.62 & 3.98 & 3.00 & 2.2933 & & \\
\hline \multirow[t]{3}{*}{3} & After tensile test & 93.53 & 3.24 & 2.43 & 2.2935 & 6.8 & 33 \\
\hline & Before recovery test & 93.40 & 3.23 & 2.43 & & & \\
\hline & After recovery test & 74.60 & 3.97 & 2.98 & 2.2933 & & \\
\hline
\end{tabular}

sample), a residual stress (4.7 $\mathrm{MPa})$ remains in the sample. This stress may be considered as the driving force responsible for SME. The driving force is more important in the stretched nonrelaxed sample. It seems that this deriving force does not depend on the temperature of the stress-relaxation test. At all temperatures (Figure 4), the curves tend to the same value (4.7 MPa). But the value of this driving force may depend on the importance of stretching. For $100 \%$ of deformation, as it was shown before, this value is 4.7 $\mathrm{MPa}$. The results of stress-relaxation test on $75 \%$ stretched samples show that this value decreased to $4 \mathrm{MPa}$.

Besides, when the implied strain is significant, the microstructure of polymer may be also modified. Some of these modifications may be irreversible. So $100 \%$ regaining of initial shape is not a guarantee for totally regaining of initial properties. In fact, the SME is generally a macroscopic phenomenon. It depends on the microstructure but this dependence is not always direct. For example, under a mechanical load some cohesive energy may be lost due to friction between macromolecules. This phenomenon may change the properties of the material without having an effect on the shape of the material.

In our opinion, there are two types of properties:

- The properties like density or Poison's ratio that are related directly to the macrostructure (shape) of the sample. This type of properties may be regained after recovery test.

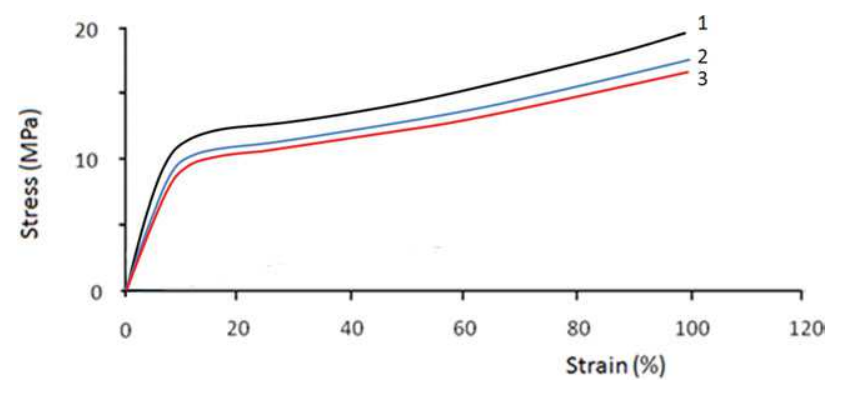

Figure 17. Stress-strain curves obtained by tensile tests at $35^{\circ} \mathrm{C}$, during successive cycles of shape memory tests at $60^{\circ} \mathrm{C}$ (1) virgin polymer, (2) after recovery test of first cycle, (3) after recovery test of second cycle. [Color figure can be viewed in the online issue, which is available at wileyonlinelibrary.com.]
- The properties like modulus or glass transition temperature that are related to the microstructure (in molecular or macromolecular scale). During shape memory test, the mechanism of their evolution is not the same as the mechanism of the SME. So this type of properties may not be regained totally after recovery test. Another physical property that is related to the microstructure is free volume. In shape memory test, as the implied deformation during tensile test is very important $(100 \%)$, the free volume fraction may be modified significantly and this modification may be irreversible after recovery test when the sample regained its initial form.

After recovery test and regaining initial shape, it is possible that the sample does not regain some of its initial properties because of microstructure irreversible changes. This microstructure changes may induce the microchange of volume, which cannot be regained after recovery test. In study of SME, generally, the authors measure the macrochange of volume. They do not show attention on this microchange of volume. In fact in the macroscopic scale, the microchanges are negligible.

\section{CONCLUSIONS}

The polyurethane under study is a shape memory polymer with a capacity of $100 \%$ recovery. It may be deformed by mechanical load and heating, fixed to obtain a temporary shape by cooling, and recovered by heating again. The viscoelastic behavior of this polymer can be modeled by a biparabolic model. It was seen

Table IV. Evolution of Young Modulus and Stress at 100\% of Strain (obtained at $35^{\circ} \mathrm{C}$ ), During Successive Cycles of Shape Memory Tests at $60^{\circ} \mathrm{C}$

\begin{tabular}{lll}
\hline & $\begin{array}{l}\text { Young } \\
\text { modulus (MPa) }\end{array}$ & $\begin{array}{l}\text { Stress at } \\
100 \% \text { strain }\end{array}$ \\
\hline Virgin polymer & 165 & 20 \\
At the end of first cycle & 128 & 17.4 \\
At the end of second cycle & 104 & 16.5 \\
\hline
\end{tabular}


that the COLE-COLE diagram related to this model, before and after tensile and relaxation tests is not the same. The change of the constants of the model indicates a change of the physical and mechanical properties of polymer. The results also showed that the constants of the model are not exactly the same for the virgin polymer and the polymer when it regained totally its original shape (100\% of recovery). Their DMTA spectra and their COLE-COLE diagram are different.

To study the properties memory effect, tensile tests have been performed at 30 and $60^{\circ} \mathrm{C}$ on virgin polymer and on the samples after recovery tests. It was shown that even $100 \%$ regaining of initial shape, the properties of virgin polymer and recovered polymer are not the same.

This difference is partially may be related to the microshape memory of polyurethane.

From the results of this work, we have two important conclusions:

- "SME" and "properties memory effect" are two different concepts; that means SMPs do not show always certain properties memory effect.

- Certain aspects of "properties memory effect" may be related to the "SME" in microscopic scale.

\section{REFERENCES}

1. Behl, M.; Zotzmann, J.; Lendlein, A. Adv. Polym. Sci. 2010, 226, 1.

2. Behl, M.; Lendlein, A. Soft Matt. 2007, 3, 58.

3. Ranta, D.; Kocsis, J. K. J. Mater. Sci. 2008, 43, 254.

4. Monkman, G. J. Mechatronics 2000, 10, 489.

5. Liu, C.; Qin, H.; Mather, P. T. J. Mater. Chem. 2007, 17, 1543.

6. Wei, Z. G.; Sandstrom, R.; Miyazaki, S. J. Mater. Sci. 1998, 33, 3743.

7. Baer, G. M.; Wilson, T. S.; Matthews, D. L.; Maitland, D. J. J. Appl. Polym. Sci. 2007, 103, 3882.
8. Lendlein, A.; Behl, M. Adv. Sci. Technol. 2009, 54, 96.

9. El Feninat, F.; Laroche, G.; Fiset, M.; Mantovani, D. $A d v$. Eng. Mater. 2002, 4, 91.

10. Golbang, A.; Kokabi, M. Eur. Polym. J. 2011, 471709.

11. Gall, K.; Yakacki, C. M.; Liu, Y.; Shandas, R.; Willett, N.; Anseth, K. S. J. Biomed. Mater. Res. Part A 2005, 73A, 339.

12. Zhang, H.; Wang, H.; Zhong, W.; Du, Q. Polymer 2009, 50, 1596.

13. Prisacariu, C. In Polyurethane Elastomer; SpringerVerlag: Wien, 2011; p 219; DOI 10.1007/978-3-7091-0514-6-6..

14. Merdas, I.; Thominette, F.; Tcharkhtchi, A.; Verdu, J. Compos. Sci. Technol. 2002, 62, 487.

15. Tcharkhtchi, A.; Bronec, P. Y.; Verdu, J. Polymer 2000, 41, 5777.

16. Tcharkhtchi, A.; Gouin, E.; Verdu, J. J. Polym. Sci. Part B: Polym. Phys. 2000, 38, 537.

17. Chen, X.; Nguyen, T. D. Mech. Mater. 2011, 43, 127.

18. Nguyen, T. D.; Qi, H. J.; Castro, F.; Long, K. N. J. Mech. Phys. Solids 2008, 56, 2792.

19. Li, G.; Xu, W. J. Mech. Phys. Solids 2011, 59, 1231.

20. Aklonis, J. J.; Macknight, W. J.; Shen, W. Introduction to Polymer Viscoelasticity; John Wiley \& Sons: New York, 1972.

21. Heuchel, M.; CU, J.; Kratz, K.; Koswella, H.; Lendlein, A. Polymer 2010, 51, 6212.

22. Srivastava, V.; Chester, S. A.; Anand, L. J. Mech. Phys. Solids 2010, 58, 1100 .

23. Tcharkhtchi, A.; Lucas, A. S.; Trotignon, J. P.; Verdu, J. Polymer 1998, V39, 1233.

24. Pittini, Y. Y.; Daneshvari, D.; Pittini, R.; Vaucher, S.; Rohr, L.; Leparoux, S.; Leuenberger, H. Eur. Polym. J. 2008, 44, 1191.

25. Perez, J. in Physique et Mécanique des Polymères amorphes; TEC\&DOC, Lavoisier: London, New York, Paris, 1992; p 173. 